\title{
Are increases in emergency use and hospitalisation always a bad thing? Reflections on unintended
} consequences and
apparent backfires

\author{
Kaveh G Shojania
}

Correspondence to

Dr Kaveh G Shojania, Faculty of Medicine, University of Toronto, Toronto, ON M5S 1A1, Canada; kaveh.shojania@sunnybrook.ca

Accepted 11 February 2019 Published Online First 7 March 2019

\section{Linked}

- http://dx.doi.org/10.1136/ bmjqs-2018-007976

\section{Check for updates}

(C) Author(s) (or their employer(s)) 2019. No commercial re-use. See rights and permissions. Published by BMJ.

To cite: Shojania KG. BMJ Qual Saf

2019;28:687-692.
Verschlimmbessern: German word meaning to make something worse in an effort to improve it

In this issue of BMJ Quality \& Safety, Snooks et al ${ }^{1}$ report a stepped-wedge trial involving 32 general practices in Wales. A web-based software program presented clinicians with estimates of patients' risk of future emergency attendance on the basis of clinical characteristics, past health services use and socioeconomic factors. Clinicians could then develop management plans which would avoid acute deteriorations necessitating emergency department attendance. Surprisingly, the intervention caused a small but statistically significant increase in hospital admissions and use of other National Health Service services.

The authors deserve congratulations here because they undertook this evaluation precisely because policies intended to improve care or reduce costs often presume the effectiveness of a certain approach when little evidence exists to support it. Targeting high-cost users of healthcare is a widely recommend approach which is harder to execute than generally recognised. ${ }^{2}$ Identifying hospitalised patients at high risk for readmission also represents a topic where predicting risk comes easily but acting effectively does not. ${ }^{3}$ But, Snooks and colleagues have shown that not only is it hard to achieve an ambitious goal, sometimes an intervention which ought to work makes things worse.

That said, increases in the use of emergency services do not imply worse quality of care. Patients who made unplanned visits to the hospital may well have had acute issues not easily dealt with in an outpatient setting. Before returning to that question, we will briefly review unintended consequences in general, followed by a focus on the subset of such situations where a change produces the opposite of its intended goal.

\section{UNINTENDED CONSEQUENCES OUTSIDE HEALTHCARE}

Sociologist Robert Merton famously drew attention to the problem of unexpected, undesirable effects with his classic essay, 'The Unanticipated Consequences of Purposive Social Action'. ${ }^{4}$ It may seem obvious now that change efforts, whether in whole societies or even single institutions, may not only fail to achieve their aims but sometimes backfire. Yet founders of the field fully expected sociology to become a predictive science on par with physics-'savoir pour prevoir, prevoir pour pouvoir' (know in order to predict, predict in order to act) in the words of 19th century French philosopher Auguste Comte.

Even without resorting to specific changes in the views of sociologists since the optimistic positivism of the 19th century, the need for humility when it comes to prediction has long been recognised. 'It's difficult to make predictions, especially about the future.' The wide range of persons to whom this wry remark has been attributed, from Nostradamus through to Mark Twain, Niels Bohr and Yogi Berra, ${ }^{5}$ attests to the long-standing recognition of our limited ability to anticipate the consequences 
of certain kinds of actions-in particular actions in complex social systems, as opposed to mechanical ones.

Case studies of the 'Law of Unintended Consequences' can fill a book. ${ }^{6}$ The topic of introducing species not native to the local ecosystem would generate a volume of its own. With ecosystems, just as with societies and large organisations, apparently simple changes to one component can produce unanticipated effects elsewhere. The work of sociologist Charles Perrow, through his Normal Accidents theory, ${ }^{7}$ highlighted how complex systems can become opaque even to expert operators. This type of complexity, when combined with 'tight coupling' between system elements, makes unintended consequences, including catastrophic accidents, all but inevitable. However, in examples such as the intervention evaluated by Snooks and colleagues, ${ }^{1}$ the issue does not arise from unexpected interactions among components of complex systems. Here, something about the intervention itself caused it to increase rather than decrease use of emergency services. So, let us move on to discussing these sorts of backfires-first using examples from outside healthcare quality improvement (table 1).

\section{FROM BARBARA STREISAND TO COBRAS AND COMPENSATORY RISK: BACKFIRE EFFECTS OUTSIDE HEALTHCARE QUALITY IMPROVEMENT}

Backfire effects occur commonly enough that several eponymous names exist for them. The 'Streisand effect ${ }^{8}$ refers to instances where efforts to suppress information promote its spread. Barbara Streisand wanted pictures of her Malibu home removed from a website where they had been incidentally collected among aerial photos documenting coastal erosion. Prior to her taking legal action, only six visitors to the website had downloaded the images of concern. The ensuing press coverage led to over 400000 visits the following month alone.

The 'cobra effect' involves the creation of perverse incentives. The British colonial government in 19th century New Delhi supposedly introduced a reward for dead cobras to curb the problem of venomous bites. The reward programme created a market for breeding cobras so people could turn them in for bounty. This might merely have constituted a failed programme except that abolishing the counterproductive reward resulted in breeders releasing their now worthless cobras. A similar example of a reward programme for rats in early 20th century Hanoi is better documented, ${ }^{9}$ and efforts to control the wild pig population in Fort Benning, Georgia, provide a relatively recent example. ${ }^{10}$

That poorly designed financial rewards can create perverse incentives hardly comes as a surprise. But economists have pointed to other less obvious backfires. The Peltzman effect ${ }^{11}$ describes increases in risky behaviours from making some situation safer-for
Table 1 'Backfire examples' from outside healthcare quality improvement

'Streisand effect' —efforts to suppress information draw more attention to it.

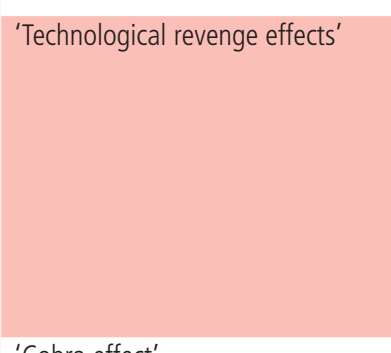

'Cobra effect'

Physicians who attempt to have a few negative reviews by patients removed from public websites risk this effect. ${ }^{42}$

\begin{tabular}{|c|c|}
\hline 'Technological revenge effects' & $\begin{array}{l}\text { A paradigmatic example from } \\
\text { Edward Tenner's book on this } \\
\text { subject }{ }^{43} \text { was the proliferation of } \\
\text { paper in the } 1980 \text { s. Far from the end } \\
\text { of paper predicted to occur with the } \\
\text { spread of personal computers, paper } \\
\text { consumption increased dramatically } \\
\text { from the ease with which printing of } \\
\text { documents and graphics could occur. }\end{array}$ \\
\hline 'Cobra effect' & $\begin{array}{l}\text { Financial incentives in some contexts } \\
\text { create perverse results-for example, } \\
\text { a bounty for dead cobras creates } \\
\text { a market for breeding cobras and } \\
\text { turning them in for the reward. }{ }^{9}\end{array}$ \\
\hline
\end{tabular}

'Compensatory risk'

Making something safer sometimes engenders riskier behaviours - for example, make cars safer and people may drive more recklessly. ${ }^{1112}$

Financial penalties for late pickups at daycare end up increasing the frequency of late pick-ups. ${ }^{44}$

Since the financial penalties were not severe, parents can (subconsciously) regard arriving late as a service for which they can pay a fee.

Providing condoms to sex workers Greater use of condoms creates a can increase unprotected sex. ${ }^{45} 46$

market for offering unprotected sex at a higher price (or puts pressure on sex workers to offer discounts for sex with condoms). ${ }^{4546}$

The government of Ghana doubled This result likely reflects the need salaries for police officers in 2010 for other concomitant interventions, to mitigate petty corruption on its such as increased monitoring for roads. Instead, bribes increased, corruption and strict enforcement of not just compared with before but penalties for accepting bribes. also to a neighbouring where the same truck drivers travelled. ${ }^{47}$

\begin{tabular}{|c|c|}
\hline $\begin{array}{l}\text { 'Scared Straight', a programme } \\
\text { aimed at deterring criminal } \\
\text { behaviour among youth by } \\
\text { exposing them to the harsh } \\
\text { realities of prison leads to more } \\
\text { offending behaviour compared } \\
\text { with doing nothing at all. }{ }^{48}\end{array}$ & $\begin{array}{l}\text { The mechanism remains unclear, but } \\
\text { may include 'peer contagion theory' } \\
\text { (law-abiding kids influenced by more } \\
\text { deviant peers) and emboldening } \\
\text { some kids by creating the impression } \\
\text { that inmates they see on their visit } \\
\text { are just 'losers who got caught'. }\end{array}$ \\
\hline $\begin{array}{l}\text { Disclosing conflicts of interest may } \\
\text { not only fail to mitigate bias but } \\
\text { actually increase it. }\end{array}$ & $\begin{array}{l}\text { Probably several mechanisms, } \\
\text { including overwhelming recipients of } \\
\text { disclosures with so much information } \\
\text { that they miss important conflicts } \\
\text { and feelings of 'moral license' among } \\
\text { those disclosing conflicts because } \\
\text { advisees 'have been warned'. } .^{51}\end{array}$ \\
\hline
\end{tabular}

instance, building safer cars may encourage more reckless driving. Peltzman probably overestimated so-called 'compensatory risk' in the specific case of automobile safety regulations, but other documented examples exist. Compensatory risk may also explain why injuries exact a heavier toll in American football than they do in rugby, despite football players wearing protective equipment, playing shorter games and tackling less 
Table 2 Predictable and less predictable undesirable effects of improvement interventions in healthcare

\begin{tabular}{|c|c|}
\hline \multicolumn{2}{|c|}{ Predictable undesirable effects ('balancing measures') ${ }^{13}$} \\
\hline $\begin{array}{l}\text { Efforts to reduce hospital } \\
\text { length of stay might increase } \\
\text { short-term readmissions. }\end{array}$ & $\begin{array}{l}\text { In their efforts to lower length of stay, } \\
\text { clinicians might discharge patients } \\
\text { prematurely. }\end{array}$ \\
\hline $\begin{array}{l}\text { Performance measures can } \\
\text { lead to inappropriate clinical } \\
\text { care, decreased provider } \\
\text { attention to other patient } \\
\text { concerns. }^{52}\end{array}$ & $\begin{array}{l}\text { Labelling patients with minimal/early } \\
\text { evidence of chronic condition makes it } \\
\text { easy to meet targets for disease control. } \\
\text { Clinicians 'play to the test' and focus } \\
\text { primarily on the few aspects of care bein } \\
\text { measured. }\end{array}$ \\
\hline
\end{tabular}

Making 'time to antibiotics' The measure encouraged clinicians to

a quality target led label patients with pneumonia and

to overdiagnosis and

overtreatment of pneumonia. administer antibiotics right away rather than taking time to sort out the diagnosis and risk missing target treatment time. $^{1415}$

Quality measures focused on inpatient falls might decrease mobility for older patients. ${ }^{5354}$

Penalising hospitals for falls (even noninjurious ones) may reduce efforts by nurses and physiotherapists to mobilise older patients in hospital.

Copayments may reduce medication adherence. Poorer patients may not fill prescriptions even for necessary medications. ${ }^{55}$

Prescribing alerts with A trial of an alert focused on the (nearly) hard stops can cause interaction between warfarin and treatment delays.

trimethoprim-sulfamethoxazole was terminated after several patients experienced potentially serious treatment delays. ${ }^{23}$

\section{Less predictable undesirable effects ('Unintended Consequences')}

Temporary increase in mortality in paediatric ICU after introducing CPOEprobably due to delayed ordering and administration of urgent medications. ${ }^{22}$

\begin{tabular}{|c|c|}
\hline $\begin{array}{l}\text { Wrong patient orders likely } \\
\text { occur more frequently with } \\
\text { CPOE compared with paper } \\
\text { charts. }\end{array}$ & $\begin{array}{l}\text { Probably various human factors such } \\
\text { as similarity of screens for all patients, } \\
\text { interruptions and simultaneously working } \\
\text { in more than one record. }\end{array}$ \\
\hline $\begin{array}{l}\text { Isolation of patients for } \\
\text { infection control increases } \\
\text { preventable adverse events. }^{29}\end{array}$ & $\begin{array}{l}\text { Probably because doctors and nurses } \\
\text { directly assess patients less frequently. }{ }^{29}\end{array}$ \\
\hline $\begin{array}{l}\text { COPD care management } \\
\text { trial terminated due to } \\
\text { threefold increased all-cause } \\
\text { mortality. }\end{array}$ & $\begin{array}{l}\text { Unclear mechanism-could have been } \\
\text { chance, but increased risk was substantia } \\
\text { (threefold) and had a p value of } 0.003 \text {, } \\
\text { well below conventional threshold of } \\
0.05 \text {. }\end{array}$ \\
\hline
\end{tabular}

COPD, chronic obstructive pulmonary disease; $C P O E$, computerised physician order entry; ICU, intensive care unit.

often. ${ }^{12}$ Clad in protective helmets and pads, players may feel safer hurtling themselves at opponents than they do when bodies will more directly collide.

\section{UNINTENDED CONSEQUENCES IN QUALITY IMPROVEMENT: FROM THE PREDICTABLE TO THE PERVERSE}

Quality improvement reports often use 'balancing measures ${ }^{13}$ to monitor predictable unintended consequences-for instance, tracking readmission rates in a project aimed at reducing length of stay (table 2). The literature on unintended consequences of performance measures constitutes a genre in itself, ${ }^{14-17}$ with many examples of Goodhart's law-when a measure becomes a target, it ceases to be a good measure. ${ }^{18} 19$ In addition, proliferation of measures from different external groups can cause measurement fatigue. ${ }^{20}$ And, of course, health information technology furnishes numerous examples of unintended consequences on workflow, morale, how clinicians interact with patients and new types of errors (table 2). ${ }^{21-28}$

Some might regard all of the 'unintended consequences' in table 2 as predictable. Maybe it seems obvious that the inconvenience of donning gowns, masks and gloves will make doctors and nurses less likely to enter the rooms of patients isolated for infection control and thus increase adverse events. ${ }^{29}$ But, some examples surely come as a surprise. For instance, 'intentional rounding,' where nurses check in frequently (eg, hourly) with every patient using a standardised protocol, may increase patient satisfaction, as well as reducing patient falls and call light use. ${ }^{30}$ The wide variation in purpose and execution of this practice ${ }^{31}$ and the mixed evidence supporting it $^{30}$ will not surprise seasoned consumers of the literature. It probably does surprise, though, to learn that one study reported a perverse increase in call light usage. Rounding every hour created for some patients the worry that nurses might not come back for quite some time, so they used their call lights more frequently than before. ${ }^{32}$

\section{BACKFIRES IN QUALITY IMPROVEMENT}

That last example brings us to the species of unintended consequence where it is not some tangential undesirable effect-like increasing call light usage when the primary interest lay with reducing fallsbut the exact opposite of the intended improvement (table 3). I have not shown examples where the 'backfire effect' resulted from an implementation issue incidental to the intervention. For instance, in a multisite study of medication reconciliation, some sites saw temporary increases in medication discrepancies due to problems arising from concomitant implementation of new electronic health record systems. ${ }^{33}$ Medication reconciliation bears no intrinsic relationship to electronic health records. Moreover, examples of medication reconciliation facilitated by electronic systems exist. ${ }^{34}$ Worsening the improvement target due to implementation problems differs from the examples in table 3, where intrinsic features of the intervention seem to have caused the backfired result.

Many examples of apparent backfires in quality improvement (table 3) arise in contexts where interventions expose health professionals to new information involving risk-the probability of an outpatient needing to visit the emergency department in the coming year, as in the study by Snooks and colleagues. ${ }^{1}$ 
Table 3 Apparent backfires in quality improvementworsening what the intervention aimed to improve

Web-based software allowing health Probably a combination of having professionals in general practices to view individual patients' scores summarising their risk of needing emergency admission significantly increased emergency hospital admissions and use of other NHS services. ${ }^{1}$

Providing intensive primary care to recently hospitalised chronically ill veterans increased rehospitalisations. ${ }^{38}$

Home-based medication review by pharmacists for recently discharged older patients increased hospital readmission rates. ${ }^{35}$

\begin{tabular}{|c|c|}
\hline $\begin{array}{l}\text { New device for earlier detection of } \\
\text { heart failure exacerbations ended } \\
\text { up increasing hospitalisations and } \\
\text { outpatient visits. }{ }^{58}\end{array}$ & $\begin{array}{l}\text { Lack of familiarity with this } \\
\text { new type of information about } \\
\text { a worrisome condition likely } \\
\text { resulted in clinicians erring on the } \\
\text { side of caution. }\end{array}$ \\
\hline
\end{tabular}

NHS, National Health Service.

In another example, pharmacists visited older patients in their homes to assess patients' understanding of and adherence to their medications, identify the need for medication adherence aids, report possible drug reactions or interactions to general practitioners and remove out-of-date drugs. ${ }^{35}$ This intervention targeted two well-known causes of hospitalisation among older patients, namely adverse drug reactions ${ }^{36}$ and medication non-adherence. ${ }^{37}$ Yet, this reasonably conceived and executed intervention produced a highly significant $30 \%$ increase in the rate of readmission $(\mathrm{p}=0.009)$.

One particularly instructive example is an intervention in the US Veterans Affairs system, ${ }^{38}$ which enrolled hospitalised medical patients who had chronic conditions frequently associated with hospitalisation and randomised roughly half to intensive primary care support, beginning with visits from clinic staff during the hospital stay to assess their postdischarge needs. The intervention achieved high fidelity in so far as 93\% of intervention patients visited the clinic at least once compared with $77 \%$ of controls $(p<0.001)$. And, intervention patients attended their primary care clinics a mean of 3.7 times vs 2.2 visits among controls $(p<0.001)$. Yet, overall, the intervention achieved the opposite of the intended result, with a higher monthly readmission rate $(0.19$ vs $0.14, p=0.005)$ and more days of rehospitalisation $(10.2$ vs $8.8, \mathrm{p}=0.041)$. In discussing these unanticipated results, Weinberger et $a l^{38}$ point out that the intervention selected patients at high risk for readmission in the first place. Moreover, 'the primary care offered to these seriously ill patients may have led to the detection and treatment of previously undetected medical problems.'

A longer follow-up period might well have produced the desired result of decreased hospitalisations. ${ }^{38}$ Over time, primary care physicians would evolve new strategies for supporting this high-risk group of patients. Yet, the pool of underuse is often of comparable magnitude to that of overuse, ${ }^{39}{ }^{40}$ just as errors of omission are probably at least as common as errors of commission. ${ }^{41}$ It is not hard to imagine that, even as outpatient providers become more comfortable or skilled managing higher risk patients without sending them to hospital, such interventions uncover other high-risk patients living in 'benign neglect'. Once identified, some of them will inevitably be referred to the hospital, and net use of acute care services may not only fail to decrease, but actually increase. In this sense, a programme that appears on the face of it to have failed (eg, increased rather than decreased admissions) may in fact have made things better for patients themselves.

Healthcare professionals of all types err on the side of caution. When interventions highlight unfamiliar types of risk, we can expect health professionals to put safety first and err on the side of sending some patients to the hospital. But, we can keep this possibility in mind when designing such interventions. An intervention highlighting new types of risk to clinicians may initially increase use of health services. Having this expectation from the outset may avoid abandoning interventions which might well achieve their intended goals if kept in place for longer.

Funding The authors have not declared a specific grant for this research from any funding agency in the public, commercial or not-for-profit sectors.

Competing interests None declared.

Patient consent for publication Not required.

Provenance and peer review Commissioned; internally peer reviewed.

\section{REFERENCES}

1 Snooks H, Bailey-Jones K, Burge-Jones D, et al. Effects and costs of implementing predictive risk stratification in primary care: a randomised stepped wedge trial. BMJ Qual Saf 2019;28:697-705.doi:

2 Wodchis WP, Austin PC, Henry DA. A 3-year study of highcost users of health care. CMAJ 2016;188:182-8.

3 Steventon A, Billings J. Preventing hospital readmissions: the importance of considering 'impactibility,' not just predicted risk. BMJ Qual Saf 2017;26:782-5.

4 Merton RK. The unanticipated consequences of Purposive social action. Am Sociol Rev 1936;1:894-904.

5 O’Toole G. Quote investigator: tracing quotations, 2013. Available: https:/quoteinvestigator.com/2013/10/20/nopredict/ [Accessed 31 Jan 2019].

6 Sherden WA. Best laid plans: the tyranny of unintended consequences and how to avoid them. Santa Barbara: Praeger, 2011. 
7 Perrow C. Normal accidents: living with high risk technologies. Princeton University Press, 1999.

8 The Economist. What is the Streisand effect? 2013. Available: https://www.economist.com/the-economist-explains/2013/04/ 15/what-is-the-streisand-effect

9 Dubner SJ. The cobra effect (EP. 96). Freakonomics radio, 2012. Available: http://freakonomics.com/podcast/the-cobraeffect-a-new-freakonomics-radio-podcast/ [Accessed 2 Feb 2019].

10 Ditchkoff SS, Holtfreter RW, Williams BL. Effectiveness of a bounty program for reducing wild pig densities: effectiveness of wild pig bounty program. Wildlife Society Bulletin 2017;41.

11 Prasad V, Jena AB. The Peltzman effect and compensatory markers in medicine. Healthc 2014;2:170-2.

12 Munger M. The dangers of safety equipment, 2017. Available: https://www.nytimes.com/2017/01/06/opinion/the-dangers-ofsafety-equipment.html

13 Toma M, Dreischulte T, Gray NM, et al. Balancing measures or a balanced accounting of improvement impact: a qualitative analysis of individual and focus group interviews with improvement experts in Scotland. BMJ Qual Saf 2018;27:547-56.

14 Wachter RM, Flanders SA, Fee C, et al. Public reporting of antibiotic timing in patients with pneumonia: lessons from a flawed performance measure. Ann Intern Med 2008;149:29-32.

15 Welker JA, Huston M, McCue JD. Antibiotic timing and errors in diagnosing pneumonia. Arch Intern Med 2008;168:351-6.

16 Schneider EC, Epstein AM. Influence of cardiac-surgery performance reports on referral practices and access to care. A survey of cardiovascular specialists. N Engl J Med 1996;335:251-6.

17 Shahian DM, Normand SL, Torchiana DF, et al. Cardiac surgery report cards: comprehensive review and statistical critique. Ann Thorac Surg 2001;72:2155-68.

18 Crawford SM. Goodhart's law: when waiting times became a target, they stopped being a good measure. BMJ 2017;359.

19 Campbell P, Boyle A, Higginson I. Should we scrap the target of a maximum four hour wait in emergency departments? BMJ 2017;359.

20 Meyer GS, Nelson EC, Pryor DB, et al. More quality measures versus measuring what matters: a call for balance and parsimony. BMJ Qual Saf 2012;21:964-8.

21 Koppel Ret al. Role of computerized physician order entry systems in facilitating medication errors. JAMA 2005;293:1197-203.

22 Han YYet al. Unexpected increased mortality after implementation of a commercially sold computerized physician order entry system. PEDIATRICS 2005;116:1506-12.

23 Strom BL, Schinnar R, Aberra F, et al. Unintended effects of a computerized physician order entry nearly HardStop alert to prevent a drug interaction. Arch Intern Med 2010;170:1578-83.

24 Shah T, Patel-Teague S, Kroupa L, et al. Impact of a national Qi programme on reducing electronic health record notifications to clinicians. BMJ Qual Saf 2019;28:10-14.

25 Shanafelt TD, Dyrbye LN, Sinsky C, et al. Relationship between clerical burden and characteristics of the electronic environment with physician burnout and professional satisfaction. Mayo Clin Proc 2016;91:836-48.

26 Toll E. A piece of my mind. The cost of technology. JAMA 2012;307:2497-8.
27 Verghese A. Culture shock - patient as icon, icon as patient. N Engl J Med 2008;359:2748-51.

28 Wong B, Kuper A, Robinson N, et al. Computerised provider order entry and residency education in an academic medical centre. Med Educ 2012;46:795-806.

29 Stelfox HT, Bates DW, Redelmeier DA. Safety of patients isolated for infection control. JAMA 2003;290:1899-905.

30 Mitchell MD, Lavenberg JG, Trotta RL, et al. Hourly rounding to improve nursing responsiveness: a systematic review. J Nurs Admin 2014;44:462-72.

31 Sims S, Leamy M, Davies N, et al. Realist synthesis of intentional rounding in hospital wards: exploring the evidence of what works, for whom, in what circumstances and why. BMJ Qual Saf 2018;27:743-57.

32 Manojlovich M, Lee S, Lauseng D. A systematic review of the unintended consequences of clinical interventions to reduce adverse outcomes. J Patient Saf 2016;12:173-9.

33 Schnipper JL, Mixon A, Stein J, et al. Effects of a multifaceted medication reconciliation quality improvement intervention on patient safety: final results of the Marquis study. BMJ Qual Saf 2018;27:954-64.

34 Etchells E, Fernandes O. Medication reconciliation: ineffective or hard to implement? BMJ Qual Saf 2018;27:947-9.

35 Holland R, Lenaghan E, Harvey I, et al. Does home based medication review keep older people out of hospital? The Homer randomised controlled trial. BMJ 2005;330.

36 Budnitz DS, Lovegrove MC, Shehab N, et al. Emergency hospitalizations for adverse drug events in older Americans. $N$ Engl J Med 2011;365:2002-12.

37 Mongkhon P, Ashcroft DM, Scholfield CN, et al. Hospital admissions associated with medication non-adherence: a systematic review of prospective observational studies. BMJ Qual Saf 2018;27:902-14.

38 Weinberger M, Oddone EZ, Henderson WG. Does increased access to primary care reduce hospital readmissions? Veterans Affairs Cooperative Study Group on primary care and Hospital readmission. N Engl J Med 1996;334:1441-7.

39 Chassin MRet al. Does inappropriate use explain geographic variations in the use of health care services? JAMA 1987;258:2533-7.

40 Leape LL, Park RE, Solomon DH. Does inappropriate use explain small-area variations in the use of health care services? JAMA 1990;263:669-72.

41 Hayward RA, Asch SM, Hogan MM, et al. SINS of omission: getting too little medical care may be the greatest threat to patient safety. J Gen Intern Med 2005;20:686-91.

42 Vartabedian B. 33 charts. Physician review sites and the Streisand effect, 2011. Available: https://33charts.com/doctorsstreisand-effect/ [Accessed 2 Feb 2019].

43 Tenner E. Technology and the revenge of unintended consequences. New York: Vintage, 1986.

44 Dubner SJ, Levitt S. Freakonomics: a rogue Economist explores the hidden side of everything. New York: William Morrow and Company, 2005.

45 Elmes J, Nhongo K, Ward H, et al. The price of sex: condom use and the determinants of the price of sex among female sex workers in eastern Zimbabwe. J Infect Dis 2014;210(suppl 2):S569-S578.

46 Rekart ML. Sex-work harm reduction. The Lancet 2005;366:2123-34.

47 Foltz JD, Opoku-Agyemang KA. Do higher salaries lower petty corruption? A policy experiment on West Africa's highways. London, UK: International Growth Centre (IGC), 2015: 49. 


\section{Editorial}

48 Petrosino A, Turpin-Petrosino C, Hollis-Peel ME, et al. 'Scared straight' and other juvenile awareness programs for preventing juvenile delinquency. Cochrane Database Syst Rev 2013.

49 Kilby B. Why Scaring Kids Out of Committing Crimes Doesn't Work. Vice 2015, 2015. Available: https://www.vice.com/en $\mathrm{ca} /$ article/kwxxba/why-scaring-kids-out-of-committing-crimesdoesnt-work-1105 [Accessed 31 Jan 2019].

50 The PLoS Medicine Editors. Does conflict of interest disclosure worsen bias? PLoS Med 2012;9:e1001210.

51 Loewenstein G, Sah S, Cain DM. The unintended consequences of conflict of interest disclosure. JAMA 2012;307:669-70.

52 Powell AA, White KM, Partin MR, et al. Unintended consequences of implementing a national performance measurement system into local practice. J Gen Intern Med 2012;27:405-12.

53 Inouye SK, Brown CJ, Tinetti ME. Medicare nonpayment, hospital falls, and unintended consequences. N Engl J Med 2009;360:2390-3.
54 Sinha SK, Detsky AS. Measure, promote, and reward mobility to prevent falls in older patients. JAMA 2012;308:2573-4.

55 Aznar-Lou I, Pottegård A, Fernández A, et al. Effect of copayment policies on initial medication non-adherence according to income: a population-based study. BMJ Qual Saf 2018;27:878-91.

56 Adelman JS, Kalkut GE, Schechter CB, et al. Understanding and preventing wrong-patient electronic orders: a randomized controlled trial. J Am Med Inform Assoc 2013;20:305-10.

57 Fan VS, Gaziano JM, Lew R, et al. A comprehensive care management program to prevent chronic obstructive pulmonary disease hospitalizations. Ann Intern Med 2012;156:673-83.

58 van Veldhuisen DJ, Braunschweig F, Conraads V, et al. Intrathoracic impedance monitoring, audible patient alerts, and outcome in patients with heart failure. Circulation 2011;124:1719-26. 